\title{
Acute kidney injury after snakebite accident treated in a Brazilian tertiary care centre
}

\author{
POLIANNA L. M. M. ALBUQUERQUE, ${ }^{1,2}$ GERALDO B. SILVA JUNIOR, ${ }^{3}$ CAMILLA N. JACINTO, ${ }^{2}$ JULIANNA B. LIMA, ${ }^{2}$ \\ CAROLINE B. LIMA, ${ }^{2}$ YAGO S. AMARAL, ${ }^{2}$ MARIA DO SOCORRO B. VERAS, ${ }^{1}$ ROSA M. S. MOTA ${ }^{4}$ and \\ ELIZABETH F. DAHER ${ }^{2}$
}

\begin{abstract}
${ }^{1}$ Toxicological Assistance Center, Instituto Dr. José Frota, ${ }^{2}$ Post-Graduation Program in Medical Sciences, Department of Internal Medicine, School of Medicine, ${ }^{4}$ Department of Statistics, Sciences Center, Federal University of Ceará, and ${ }^{3}$ Post-Graduation Program in Collective Health, Health Sciences Center, School of Medicine, University of Fortaleza, Fortaleza, Ceará, Brazil
\end{abstract}

\section{KEY WORDS:}

acute kidney injury, complications, ophidic accident, risk factors, snakebite.

\section{Correspondence:}

Dr Elizabeth F. Daher, Rua Vicente Linhares, 1198, CEP: 60135-270, Fortaleza, Ceará, Brazil. Email: ef.daher@uol.com.br

Accepted for publication 11 August 2014 Accepted manuscript online 14 August 2014

doi:10.1111/nep.12327

\section{SUMMARY AT A GLANCE}

The manuscript describes the epidemiology and clinical features of AKI among victims of snake bite in Brazil. Importantly, a significant proportion did not show full renal functional recovery.

\section{ABSTRACT:}

Aim: Acute kidney injury (AKI) is one of the main causes of morbidity and mortality in cases of envenomation by venomous snakes. The present study was carried out to investigate the clinical and laboratory manifestations in accidents with venomous snakes and the risk factors associated with AKI in these accidents.

Methods: A retrospective study was carried out with patients victims of snakebite admitted to a reference centre. AKI was defined according to the RIFLE and AKIN criteria.

Results: A total of 276 patients were included, of which $230(83.7 \%)$ were males. AKI was observed in 42 cases $(15.2 \%)$. The mean genus involved in the accidents was Bothrops $(82.2 \%)$. Mean age of patients with AKI was higher than in patients without AKI ( $43 \pm 20$ vs. $34 \pm 21$ years, $P=0.015)$. The time elapsed between the accident and medical care was higher in the AKI group ( $25 \pm 28$ vs. $14 \pm 16 \mathrm{~h}, P=0.034$ ), as well as the time elapsed between the accident and the administration of antivenom $(30.7 \pm 27$ vs. $15 \pm 16 \mathrm{~h}$, $P=0.01$ ). Haemodialysis was required in $30 \%$ of cases and complete renal function recovery was observed in $\mathbf{5 4 . 8 \%}$ of cases at hospital discharge. There were four deaths, none of which had AKI. Factors associated with AKI were haemorrhagic abnormalities $(P=0.036$, OR $=6.718,95 \%$ CI: $1.067-$ 25.661) and longer length of hospital stay $(P=0.004, \mathrm{OR}=1.69,95 \% \mathrm{CI} 1.165-$ 2.088).

Conclusion: Acute kidney injury is an important complication of snakebite accidents, showing low mortality, but high morbidity, which can lead to partial renal function recovery.
Envenomation by venomous snakes belongs to the group of main neglected tropical diseases ${ }^{1}$ and constitutes an important public health problem. It has a worldwide distribution, affecting mainly rural populations in Asia, Africa, Latin America and Oceania. ${ }^{1}$ In Latin America, there are four groups of clinically relevant poisonous snakes: Bothrops, Crotalus, Lachesis and Micrurus. ${ }^{2}$

In Brazil, there has been an increase in the number of envenomation accidents caused by poisonous animals reported from 1986 to mid-2012, according to data from the Ministry of Health (http://portal.saude.gov.br/portal/ arquivos/pdf/clipping30072010.pdf). The main venomous snakes involved in this type of accident in Brazil are similar to those observed in Latin America. Acute kidney injury (AKI) is a result of the accidents with the genus Bothrops and Crotalus. $^{2}$

Snakebite-associated AKI in tropical countries and its impact on morbidity and mortality has been the subject of some studies. ${ }^{2,3}$ The clinical picture resulting from snakebites varies according to the involved species and the amount of inoculated venom. Systemic manifestations consist mainly of renal, ${ }^{3}$ haemorrhagic (haematuria, haematemesis, brain and cavity haemorrhages) and neurological alterations, common in Crotalus accidents (paresthesia, paralysis with craniocaudal 
progression, starting with ptosis and ophthalmoplegia, which may develop into paralysis of the respiratory muscles resulting in acute respiratory failure). ${ }^{4}$

The present study was carried out to investigate the characteristics of AKI associated with venomous snakebites and the involved risk factors.

\section{METHODS}

\section{Patients}

This is a retrospective study carried out in a tertiary hospital in the city of Fortaleza, state of Ceará, Brazil.

We included all the patients treated at Instituto Dr. José Frota from January 2003 to December 2012, with a history of poisonous snakebite. All the patients included in the study were hospitalized due to the accident.

The victims of non-poisonous $(n=243)$ or non-identified snakebites $(n=628)$ were excluded. One patient that was diagnosed with heart failure (clinical syndrome that result in any structural or functional impairment of ventricular filling or ejection of blood - ejection fraction $\leq 40 \%$, according to the Guidelines of the American Heart Association), ${ }^{5}$ was excluded. This patient, victim of a venomous snakebite, had heart failure, but not AKI.

The snakes were identified by the patients themselves. In some cases, the patients brought the snake to the hospital. The physician assessed the site of the bite and classified the snake through anamnesis and laboratory exams were requested.

A semistructured form was used for data collection from each patient, containing epidemiological, clinical and laboratory information.

The study protocol was reviewed and approved by the Committee of Ethics from Instituto Jose Frota, in Fortaleza, Brazil (protocol $119 / 12$ ).

\section{Definitions}

Acute kidney injury was defined according to the RIFLE and AKIN classifications, according to creatinine levels within the first $48 \mathrm{~h}$ after hospital admission. ${ }^{6,7}$ Baseline creatinine was the one measured $48 \mathrm{~h}$ before its elevation. Three or more serum creatinine measurements were obtained from each patient studied during this period. A time constraint of $48 \mathrm{~h}$ for the diagnosis of AKI was proposed. Creatinine measurements were performed using the modified kinetic Jaffé method, at $500 \mathrm{~nm}$, without deproteinization. Patients were classified according to the worst criteria (creatinine or urine output). Oliguria was considered as urinary volume $<400 \mathrm{~mL} /$ day after $24 \mathrm{~h}$ of adequate volume replacement.

Renal function recovery was based on the creatinine levels at the time of hospital discharge. Partial recovery of renal function at the time of discharge was considered as creatinine above the basal level (i.e., patients still classified as one of the RIFLE or AKIN stages at the time of hospital discharge).

\section{Study groups}

Patients were classified into two groups: patients with normal renal function (Non-AKI) and patients with AKI. When comparing the two groups, differences in clinical manifestations, laboratory findings and risk factors for AKI were assessed.

\section{Clinical and laboratorial parameters}

At physical examination, signs and symptoms were evaluated and the following aspects were recorded: age, gender, snake species, severity of accident, the median time between the accident and the administration of the antivenom, dose of antivenom, length of hospital stay and haemorrhagic manifestations. The use of herbal remedies was investigated, and their use constituted an exclusion criterion, as some herbs are nephrotoxic and could be responsible for AKI development.

The following laboratory parameters were evaluated: serum creatinine, urea, sodium, potassium, haematocrit, haemoglobin, leukocytes, platelets, prothrombin time (PT) and partially activated thromboplastin time (aPTT)

\section{Treatment protocol}

Patients were classified according to the severity of the snakebite accident using the Brazilian Ministry of Health criteria, based on local and systemic clinical manifestations established in specific tables for each accident (see appendix). The administration of specific antivenom was performed according to those criteria.

\section{Statistical analysis}

The results are expressed in tables and means (mean \pm SD) for quantitative variables. Univariate and multivariate analyses of clinical and laboratory data were performed using the SPSS program, release 21.0, 2012 for MacBook (SPSS Inc. Chicago, IL, USA), to investigate the possible risk factors associated with acute kidney injury.

The Kolmogorov-Smirnov test was used to verify the normal distribution of continuous variables. The Levene test was used to compare the variability of the means. In the of normal data distribution, the comparison between two means was made by Student's $t$-test. In case of non-normal data, the Mann-Whitney test was applied and the variables were expressed as medians. Analysis of variance (ANOVA) was used to compare means between three or more independent groups, with a post-hoc analysis through Bonferroni's method. Pearson's $\chi^{2}$ test, likelihood ratio and Fisher's exact test were used for association and homogeneity tests in the distribution of categorical data.

Odds ratio was estimated when the association was significant. Confidence intervals of $95 \%$ were calculated. The factors included in the multivariate model (logistic regression) through the Backward method, were those factors that showed statistical significance level $<20 \%$ in the univariate analysis (Mann-Whitney and $\chi^{2}$ test). Statistical significance was set at 5\% $(P<0.05)$.

\section{RESULTS}

\section{Demographic and clinical characteristics at admission}

A total of 276 patients were included in the study; 230 $(83.7 \%)$ were males; $146(85.5 \%)$ lived in rural areas. 
The AKI group $(n=42)$ had a mean age of $43 \pm 20$ years (median 48), of which $32(76.2 \%)$ were males and 38 $(90.5 \%)$ were from the rural area. Of the snake species involved in the accident, $30(71.4 \%)$ were Bothrops, 10 $(23.8 \%)$ Crotalus and two $(4.8 \%)$ Micrurus. As for the severity of the accident, nine (21.4\%) were mild, 19 (45.2\%) moderate and $14(33.3 \%)$ severe. The median time between the accident and antivenom administration was $24 \mathrm{~h}$ (3-96 h). The median time of hospital stay was 8 days, (2-38 days). The median dose of administered antivenom was 8 vials (0-33 vials) (Table 1$)$.

The non - AKI group $(n=198)$ had a mean age of $34 \pm 21$ years (median 33), of which $198(84.6 \%)$ were males and $198(85.3 \%)$ were from the rural area. Of the snake species involved in the accident, $197(84.2 \%)$ were Bothrops, 18

Table 1 Demographic characteristics of patients who developed or not acute kidney injury (AKI), victims of accidents with venomous snakes

\begin{tabular}{|c|c|c|c|}
\hline & AKI $(n=42)$ & Non-AKI $(n=234)$ & $P$ \\
\hline \multicolumn{4}{|l|}{ Gender } \\
\hline Male & $32(76.2 \%)$ & $198(84.6 \%)$ & 0.182 \\
\hline Female & $10(23.8 \%)$ & $36(15.4 \%)$ & \\
\hline Age (years) † & $43 \pm 20$ & $34 \pm 21$ & 0.015 \\
\hline \multicolumn{4}{|l|}{ Area } \\
\hline Rural & $38(90.5 \%)$ & $198(85.3 \%)$ & 0.47 \\
\hline Urban & $4(9.5 \%)$ & $34(14.7 \%)$ & \\
\hline \multicolumn{4}{|l|}{ Snake species } \\
\hline Bothrops & $30(71.4 \%)$ & $197(84.2 \%)$ & 0.015 \\
\hline Crotalus & $10(23.8 \%)$ & $18(7.7 \%)$ & \\
\hline Micrurus & $2(4.8 \%)$ & $17(7.3 \%)$ & \\
\hline Lachesis & - & $2(0.9 \%)$ & \\
\hline \multicolumn{4}{|l|}{ Severity of accident } \\
\hline Mild & $9(21.4 \%)$ & 30 (12.8\%) & \\
\hline Moderate & $19(45.2 \%)$ & $154(65.8 \%)$ & 0.741 \\
\hline Severe & $14(33.3 \%)$ & $50(21.4 \%)$ & \\
\hline $\begin{array}{l}\text { Time between the accident } \\
\text { and antivenom } \\
\text { administration (hours) } \neq\end{array}$ & $24.0(3-96)$ & $9.0(1-72)$ & 0.01 \\
\hline Length of hospital stay (days) $\ddagger$ & $8.0(2-38)$ & $3.0(1-8)$ & $<0.001$ \\
\hline Dose of antivenom (vials)ł & $8(0-33)$ & $8(0-25)$ & 0.196 \\
\hline
\end{tabular}

(7.7\%) Crotalus and 17 (7.3\%) Micrurus. As for the severity of the accident, 30 (12.8\%) were mild, 154 (65.8\%) moderate and $50(21.4 \%)$ severe. The median time between the accident and antivenom administration was $9 \mathrm{~h}(1-72 \mathrm{~h})$. The median time of hospital stay was 3 days, (1-8 days). The median dose of administered antivenom was 8 vials (0-25 vials) (Table 1 ).

\section{Distribution of patients according to the RIFLE and AKIN classifications}

Acute kidney injury was observed in 42 (15.2\%) patients according to the AKIN and 41 (18.9\%) patients according to the RIFLE criteria. Patients were classified as AKIN 1 (15; $35.7 \%), \operatorname{AKIN} 2(3 ; 7.1 \%), \operatorname{AKIN} 3(24 ; 57.1 \%), \mathrm{R}(12$; $29.2 \%)$, I $(5 ; 12.2 \%)$ and $\mathrm{F}(24 ; 58.5 \%)$. Due to the small number of patients in each group, only two groups were used in the analysis: AKI and non-AKI, determined by serum creatinine, according to the AKIN criteria.

\section{Comparison of laboratory tests and clinical findings}

A comparison of clinical characteristics between patients classified as AKI and non-AKI is summarized in Table 2. The groups differed regarding the presence of haemorrhagic alterations (OR 3.016, $P=0.001$ ) and lesion site (OR 0.47, $P=0.022)$. As for PT (OR 0.383, $P=0.005)$ and aPTT (OR $0.478, P=0.042$ ) alterations in the groups, there was statistical difference between them. The presence of myalgia showed a tendency to significance, but did not differ between the groups $(P=0.053)$.

Among the patients with haemorrhagic alterations $(n=274), 19$ developed concomitant AKI.

The mean values of creatinine and urea at admission and at discharge were higher in the AKI group (Table 3). Haemoglobin $(9.4 \pm 2.5$ vs. $12.7 \pm 2.5, P<0.0001)$ and haematocrit $(28.9 \pm 9.0$ vs. $39.1 \pm 11.0 ; P=0.002)$ levels and platelet count (95 $690 \pm 79200.8$ vs. $212227 \pm 90$ 913; $P<0.0001$ ) were lower in the AKI group. Leukocyte count (13 568.3 \pm 5178.4 vs. $11135 \pm 3011.5 ; \quad P=0.044)$ was lower in the non-AKI group (Table 3).

Table 2 Clinical aspects of acute kidney injury (AKI) and non-AKI groups in victims of accidents with venomous snakes

\begin{tabular}{|c|c|c|c|c|c|c|}
\hline & \multirow[t]{2}{*}{$\mathrm{AKI}(n=42)$} & \multirow[t]{2}{*}{ Non-AKI $(n=234)$} & \multirow[t]{2}{*}{$P$} & \multirow[t]{2}{*}{ OR } & \multicolumn{2}{|c|}{$95 \% \mathrm{Cl}$} \\
\hline & & & & & $\mathrm{LL}$ & UL \\
\hline Nervous system alteration & $12(28.6 \%)$ & $38(16.4 \%)$ & 0.06 & 2.042 & 0.960 & 4.34 \\
\hline Haemorrhagic manifestation & $22(52.4 \%)$ & $62(26.7 \%)$ & 0.001 & 3.016 & 1.541 & 5.905 \\
\hline Local lesion & $24(57.1 \%)$ & $172(74.5 \%)$ & 0.022 & 0.457 & 0.232 & 0.902 \\
\hline Palpebral ptosis or diplopia & $7(16.7 \%)$ & $18(7.8 \%)$ & 0.065 & 2.378 & 0.926 & 6.107 \\
\hline Myalgia & $8(19 \%)$ & $21(9.1 \%)$ & 0.053 & 2.364 & 0.970 & 5.764 \\
\hline Altered PT & $9(21.4 \%)$ & $88(37.9 \%)$ & 0.005 & 0.383 & 0.187 & 0.784 \\
\hline Altered aPTT & $8(19 \%)$ & 71 (30.3\%) & 0.042 & 0.478 & 0.220 & 1.037 \\
\hline
\end{tabular}

Platelets, prothrombin time (PT) and partially activated thromboplastin time (aPTT). $\chi^{2}$ test. Significant $P<0.05$. 
Table 3 Comparison of laboratory findings between the groups of patients that developed acute kidney injury (AKI) and those who did not develop it (Non-AKI)

\begin{tabular}{|c|c|c|c|}
\hline & $\mathrm{AKI}(n=42)$ & Non-AKI $(n=274)$ & $P$ \\
\hline Sodium (mEq/L)† & $137.4( \pm 5.2)$ & $140( \pm 5.7)$ & 0.06 \\
\hline Potassium (mEq/L)† & $4.5( \pm 0.9)$ & $4.0( \pm 0.4)$ & 0.17 \\
\hline $\begin{array}{l}\text { Creatinine at } \mathrm{AKI} \\
\text { diagnosis }(\mathrm{mg} / \mathrm{dL}) \dagger\end{array}$ & $3.07( \pm 2.7)$ & $0.94( \pm 0.38)$ & $<0.0001$ \\
\hline $\begin{array}{l}\text { Creatinine at } \\
\text { discharge }(\mathrm{mg} / \mathrm{dL}) \dagger\end{array}$ & $3.0( \pm 2.9)$ & $0.9( \pm 0.35)$ & $<0.0001$ \\
\hline $\begin{array}{l}\text { Urea at AKI diagnosis } \\
\qquad(\mathrm{mg} / \mathrm{dL}) \dagger\end{array}$ & $107.1( \pm 74.1)$ & $37.6( \pm 27.5)$ & $<0.0001$ \\
\hline $\begin{array}{l}\text { Urea at discharge } \\
\qquad(\mathrm{mg} / \mathrm{dL}) \dagger\end{array}$ & $72.9( \pm 50.72)$ & $32.4( \pm 16.3)$ & $<0.0001$ \\
\hline Haemoglobin (g/dL) $\neq$ & $9.42( \pm 2.46)$ & $12.7( \pm 2.52)$ & $<0.0001$ \\
\hline Haematocrit (\%)‡ & $28.86( \pm 9.0)$ & $39.1( \pm 11.0)$ & 0.002 \\
\hline $\begin{array}{l}\text { Leukocyte count } \\
\qquad\left(/ \mathrm{mm}^{3}\right) \ddagger\end{array}$ & $13568.3( \pm 5178.4)$ & $11135( \pm 3011.45)$ & 0.044 \\
\hline $\begin{array}{l}\text { Platelet count } \\
\qquad\left(/ \mathrm{mm}^{3}\right) \ddagger\end{array}$ & $95690.0( \pm 79200.8)$ & 212227 ( \pm 90913$)$ & $<0.0001$ \\
\hline
\end{tabular}

†Mann-Whitney. $\ddagger$ Student’s $t$-test. Significant: $P<0.05$.

\section{Clinical outcome}

Among the patients who developed AKI, 25 (64.1\%) achieved renal function recovery, $12(30.8 \%)$ had partial recovery, no patient died and two $(5.1 \%)$ were transferred to another reference hospital. Of the patients who did not have AKI (non-AKI) four (1.7\%) died, and two (0.9\%) were transferred to another hospital.

The causes of death were gastrointestinal bleeding (1), CNS haemorrhage (1), anaphylaxis to the antivenom (1) and haemorrhagic diastasis (1). Of the patients who developed AKI, 13 (30.6\%) underwent haemodialysis.

\section{Risk factors for AKI}

Independent factors associated with AKI were the presence of haemorrhagic alterations on admission ( $\mathrm{OR}=6.718,95 \%$ $\mathrm{CI}=1.067$ to $25.661, P=0.036)$ and a longer hospital length of stay $(\mathrm{OR}=1.698,95 \% \mathrm{CI}=1.165-2.088, P=0.004)$, as shown in Table 4.

\section{DISCUSSION}

The present study showed important clinical and laboratory aspects of snakebite-associated AKI. As the kidney is a highly vascularized organ, it is very susceptible to toxins. ${ }^{8} \mathrm{AKI}$ is an important complication of envenomation accidents, being one of the main causes of mortality. ${ }^{9}$

The predominance of the male gender was observed in the group that developed AKI $(76.2 \%)$, as well as in the group who did not develop it $(84.6 \%)$, with no difference between these groups regarding gender. Many studies in the literature have demonstrated the predominance of males in snakebite
Table 4 Factors associated with acute kidney injury (AKI) in 276 patients, victims of accidents with venomous snakes

\begin{tabular}{llllr}
\hline Acute Kidney Injury & $P$ & OR & \multicolumn{2}{c}{$95 \% \mathrm{Cl}$} \\
\cline { 4 - 5 } & & & $\mathrm{LL}$ & $\mathrm{UL}$ \\
\hline Length of hospital stay & 0.004 & 1.698 & 1.165 & 2.088 \\
Haemorrhagic manifestation & 0.036 & 6.718 & 1.067 & 25.661 \\
\hline
\end{tabular}

Variables analyzed: myalgia, days of hospitalization, haemorrhagic alterations, age, lesion site, Bothrops sp, time until antivenom administration, altered prothrombin time (PT) and altered partially activated thromboplastin time (aPTT).

accidents. ${ }^{10-14}$ However, studies have shown that the distribution of the male gender was not different in the groups that did or did not develop AKI. ${ }^{15-17}$ Feitosa et al. ${ }^{18}$ has described the predominance of males in the state of Ceará, Brazil (over $70 \%$ ). Borges et al., ${ }^{19}$ in a study carried out in the Amazon region, also showed a predominance of males $(81.3 \%)$.

Patients who developed AKI in the study were older, with a significant statistical difference between the groups. Some studies have shown a prevalence of AKI in older patients. ${ }^{16,17}$ Pinho et al. ${ }^{15}$ showed a predominance of AKI in younger patients, as they concentrate larger amounts of venom in a lower body surface area. On the other hand, older patients would have less viable glomerular mass, which could make them more susceptible to toxins.

The predominant area of origin in both AKI (90.5\%) and non-AKI $(85.3 \%)$ groups was the rural area, with no statistical difference between the groups, corroborated by the fact that the accident is associated with people's activities in the countryside. Akani et al., ${ }^{20}$ in their study, highlighted a strong correlation between human activity type (rural or urban) and the occurrence of snakebite accidents.

In our study, the snake species distribution in the AKI and non-AKI groups showed a predominance of the Bothrops genus in both groups, consistent with the fact that this is the most prevalent snake species in Brazil, with more than 30 species being found throughout the national territory. ${ }^{8}$ Other studies have obtained the same finding. ${ }^{13,14,21}$ The second most prevalent species involved in snakebite accidents in this study is the Crotalus. It is important to note the strong association between the Crotalus species and the development of AKI. AKI is more commonly seen in Crotalus than in Bothrops accidents, as the crotalic venom is more nephrotoxic. ${ }^{22}$

As for the severity of the accidents, most were classified as being of moderate severity followed by severe, as observed in both groups (AKI and non-AKI), with no statistical difference. According to Amaral et al. ${ }^{4}$ most snakebite accidents reported are mild ones, which corroborates the findings of Lima et al., ${ }^{12}$ Oliveira et al. ${ }^{14}$ and Lemos et al. ${ }^{21}$ Mise et al. ${ }^{11}$ described the prevalence of moderate cases followed by severe cases, data that are consistent with the findings in our study.

Many studies have shown a tendency to the development of AKI in patients that waited longer between the snakebite 
and antivenom administration. ${ }^{15-17}$ In our study, the multivariate analysis showed no significant difference between AKI and non-AKI groups regarding the time elapsed between the bite and antivenom administration, which is in conflict with data from some studies that defined longer time between the bite and antivenom administration as an independent risk factor for the development of AKI. ${ }^{15,16}$ As this is a retrospective study, there may have been variables that were not informed, which could have influenced the analysis of this parameter (time elapsed between the snakebite and antivenom administration). The small sample size may have interfered with the results.

Regarding the length of hospital stay, AKI and non-AKI groups differed significantly, which was consistent with the literature. ${ }^{15-17}$ There was an association between length of stay and the development of AKI, which may represent major clinical complications for the patient, leading to longer hospital stays.

The presence of haemorrhagic disorders, even without coagulation alterations, was an important finding in this study. Bleeding is one of the most important effects induced by snakebites. Damage to the microvasculature is a consequence of metalloproteinase action, which leads to distension, oedema and rupture of capillary walls. ${ }^{23}$ Santoro et al. ${ }^{24}$ showed the presence of a platelet-inhibitory factor found in the plasma of rabbits injected with Bothrops venom and described the presence of fibrin thrombi in the histological analysis of lungs and kidneys of these rabbits, suggesting that renal abnormalities can occur even without coagulation alterations (PT and aPTT).

The association between haemorrhagic manifestations and AKI development may represent a typical feature of the venom of poisonous snakes found in north-eastern Brazil, mainly represented in the study by the Bothrops species. However, the association between haemorrhagic manifestations and AKI development should be interpreted with caution, considering the confidence interval was too long.

Fonseka et al..$^{25}$ demonstrated that haemorrhagic manifestations secondary to snakebites can be severe. Silva et al. ${ }^{26}$ reported the presence of petechiae and severe congestion in the lungs, kidneys and gastrointestinal tract in victims of snakebite accidents. Maduwage et al. ${ }^{27}$ reported cases of fatal snakebite accidents that developed consumptive coagulopathy and AKI. Moriarity et al., ${ }^{28}$ based on a retrospective study, concluded that coagulation tests should be requested for all patients, as it would be impossible to identify which groups would be more susceptible to bleeding. The importance of haemorrhagic manifestations as a risk factor for the development of AKI can indicate a particular physiopathological aspect of the snakes found in northeastern Brazil.

In the present study, laboratory parameters showed higher levels of urea and creatinine in patients with AKI, when compared to the non-AKI group. These results were expected, according to the use of AKIN and RIFLE classifications. The haemoglobin and haematocrit levels in the group that developed AKI were lower, with a statistically significant difference $(P<0.0001, P=0.002)$. This fact may represent haemorrhagic alterations secondary to Bothrops poisoning, resulting from the action of zinc-containing metalloproteinases, which produce lesions in the basal capillary membrane, associated with thrombocytopenia and coagulation disorders. ${ }^{4}$ The haemoglobin and haematocrit levels were not included in the multivariate analysis, as several cases' records lacked this information.

Athappan et al. ${ }^{16}$ described the presence of intravascular haemolysis as an independent risk factor for the development of AKI $(\mathrm{OR}=3.2, \quad P=0.01)$, which justifies the decrease in platelet and haemoglobin levels in our sample. Platelets can also be reduced due to the coagulation system activation and intravascular fibrin formation after factor $\mathrm{X}$ activation by the bothropic venom. ${ }^{29}$

The study mortality was $1.4 \%$ in snakebite accidents with poisonous snakes, which was considered low, consistent with data in the national literature, ${ }^{4,12,14,21}$ showing the low lethality of snakebites. Most patients were cured; however, 13 patients persisted with renal function deficit until hospital discharge.

In summary, AKI was an important complication of snakebite accidents in our study. Morbidity can be high, leading to persistent kidney dysfunction. A longer duration of hospital stay and the presence of haemorrhagic alterations were independent risk factors for the development of AKI.

As the present is a retrospective study, one of its limitations was the lack of information in the medical records, which prevented some statistical inferences. Prospective studies may further elucidate the factors that lead to snakebite-associated AKI. At admission, some patients showed higher levels of creatinine with no variation during hospitalization. This fact should be seen as a limitation/bias in the diagnosis of AKI (these cases were excluded from the analysis, as they did not meet the RIFLE or AKIN criteria). This is a single-centre study and it is necessary to perform similar investigations in other centres to better analyze the results and to assess the impact of these accidents in our country.

\section{REFERENCES}

1. Gutiérrez JM, Theakston DG, Warrell DA. Confronting the neglected problem of snakebite envenoming: The need for a global partnership. PLoS Med. 2006; 3: el50.

2. Pinho FMO, Yu L, Burdmann EA. Snakebite-induced kidney injure in Latin America. Semin. Nephrol. 2008; 28: 354-62.

3. Amaral CFS, Rezende NA, Silva OA et al. Insuficiência renal aguda secundária a acidentes ofídicos botrópico e crotálico: Análise de 63 casos. Rev Inst Med Trop São Paulo 1986; 28: 220-7.

4. Amaral CFS, Bucaretchi F, Araújo FAA et al. Manual de diagnóstico e tratamento de acidentes por animais peçonhentos, $2^{\text {a }}$ edição. Brasília: Ministério da Saúde, Fundação Nacional de Saúde, 9-36. 2001. 
5. Yancy CW, Jessup M, Bozkurt B et al. Guideline for the management of heart failure: Executive summary. Circulation 2013; 128: $1810-52$.

6. Bellomo R, Ronco C, Kellum JA, Mehta RL, Palevsky P. Acute renal failure - Definition, outcome measures, animal models, fluid therapy and information technology needs: The Second International Consensus Conference of Acute Dialysis Quality Initiative (ADQI) Group. Crit. Care 2004; 8: R204-R212.

7. Mehta RL, Kellum JA, Shah SV et al. Acute kidney injury network (AKIN): Report of an initiative to improve outcomes in acute kidney injury. Crit. Care 2007; 11: R31.

8. Sitprija V, Sitprija S. Renal effects and injury induced by animal toxins. Toxicon 2012; 60: 943-53.

9. Chugh KS. Snake bite induced acute renal failure in India. Kidney Int. 1989; 35: 891-907.

10. Bochner R, Struchiner CJ. Epidemiologia dos acidentes ofídicos nos últimos 100 anos no Brasil: uma revisão. Cad Saúde Pública 2003; 19: 7-16.

11. Mise Y, Lira-da-Silva M, Carvalho FM. Envenenamento por serpentes do gênero Bothrops no estado da Bahia: aspectos epidemiológicos e clínicos. Rev. Soc. Bras. Med. Trop. 2007; 40: 563-73.

12. Lima JS, Martelli Júnior H, Martelli DR et al. Perfil dos acidentes ofídicos no norte do Estado de Minas Gerais, Brasil. Rev. Soc. Bras. Med. Trop. 2009; 42: 561-4.

13. Lima AC, Campos CE, Ribeiro JR. Perfil epidemiológico de acidentes ofídicos do Estado do Amapá. Rev. Soc. Bras. Med. Trop. 2009; 42: 329-35.

14. Oliveira FN, Brito MT, Morais ICO et al. Accidents caused by Bothrops and Bothropoides in the state of Paraíba: Epidemiological and clinical aspects. Rev. Soc. Bras. Med. Trop. 2010; 43: 662-7.

15. Pinho FMO, Zanetta DM, Burdmann EA. Acute renal failure after Crotalus durissus snakebite: A prospective survey on 100 patients. Kidney Int. 2005; 67: 659-67.

16. Athapan MG, Balaji UV, Navaneethan PT. Acute renal failure in snake envenomation: A large prospective study. Saudi J. Kidney Dis. Transpl. 2008; 19: 404-10.

17. Harshavardhan L, Lokesh AJ, Tejeshwari HL, Halesha BR, Siddharama SM. A study on the acute kidney injury in snake bite victims in a tertiary care centre. J. Clin. Diagn. Res. 2013; 7: 853-6.
18. Feitosa R, Melo I, Monteiro H. Epidemiologia dos acidentes por serpentes peçonhentas no estado do Ceará - Brasil. Rev. Soc. Bras. Med. Trop. 1997; 30: 295-301.

19. Borges C, Sadahiro M, Santos M. Aspectos epidemiológicos e clínicos dos acidentes ofídicos ocorridos nos municípios do Estado do Amazonas. Rev. Soc. Bras. Med. Trop. 1999; 32: 637-46.

20. Akani GC, Ebere N, Eniang EA, Petrozzi F, Politano E, Luiselli L. Correlation between anual activity patterns of venomous snakes and rural people in the Niger Delta, Southern Nigeria. J. Venom. Anim. Toxins Incl. Trop. Dis. 2013; 19: 2-8.

21. Lemos J, Almeida T, Fook S, Paiva A, Simões M. Epidemiologia dos acidentes ofídicos notificados pelo Centro de Assistência e Informação Toxicológica de Campina Grande (Ceatox-CG), Paraíba. Rev. Bras. Epidemiol. 2009; 12: 50-9.

22. Santos MFL, Farani MC, Roche PN. Acute Kidney Injury in Bothrops sp. and Crotalus sp. envenomation: Critical review of the literature. J. Bras. Nefrol. 2009; 31: 132-8.

23. Escalante T, Rucavo A, Fox JW, Gutiérrez JMK. Key events in microvascular damage induced by snake venom hemorrhagic metalloproteinases. J. Proteomics 2011; 74: 1781- 94.

24. Santoro ML, Sano-Martins IS. Platelet dysfunction Bothrops jararaca snake envenomation in rabbits. Thromb. Haemost. 2004; 92: 369-83.

25. Fonseka CL, Jeevagan V, Gnanathasan CA. Life threatening intracerebral haemorrhage following saw-scaled viper (Echis carinatus) envenoming-authenticated case report from Sri Lanka. BMC Emerg. Med. 2013; 13: 5.

26. Silva A, Gunawardena P, Weilgama D, Maduwage K, Gawarammana I. Comparative in vivo toxicity of venoms from South Asian hump- nosed pit vipers (Viperidae: Crotalinae: Hypnale). BMC Res. Notes 2012; 5: 471.

27. Maduwage K, Kularatne K, Gawarammana I. Coagulopathy, acute kidney injury and death following Hypnale zara envenoming The first case report from Sri Lanka. Toxicon 2011; 58: 641-3.

28. Moriaty RS, Dryer S, Replogle W, Summers R. The role for coagulation markers in mild snakebite envenomations. West. J. Emerg. Med. 2012; 13: 68-74.

29. Sgrinolli L, Mendes G, Carlos G, Burdmann E. Acute kidney injury caused by bothrops snake venom. Nephron Clin. Pract. 2011; 119: 131-7.

\section{APPENDIX}

Table A1 Bothropic accident: classification regarding severity and recommended antivenom

\begin{tabular}{|c|c|c|c|}
\hline \multirow{2}{*}{ Manifestations and treatment } & \multicolumn{3}{|c|}{ Classification } \\
\hline & Mild & Moderate & Severe \\
\hline LOCAL - pain/oedema/ecchymosis & Absent or discrete & Evident & Intense† \\
\hline SYSTEMIC - severe haemorrhage/shock/anuria & Absent & Absent & Present \\
\hline Time of coagulation (TC $\ddagger)$ & Normal or Altered & Normal or Altered & Normal or Altered \\
\hline Antivenom (no. vials) ABS/ABCS/ABLS & $2-4$ & $4-8$ & 12 \\
\hline Route of administration & Intravenous & & \\
\hline
\end{tabular}

†Intense local manifestations may be the only criterion for severity classification. $\ddagger$ Normal TC: up to 10 min; prolonged TC: from 10 to 30 min; incoagulable TC: $>30$ min. ABCS, anti-bothropic-crotalic serum; ABLS, anti-bothropic-lachetic serum; ABS, anti-bothropic serum. Source: Adapted from the Ministry of Health, 2001. 
PLMM Albuquerque et al.

Table A2 Crotalic accident: classification regarding severity and recommended antivenom

\begin{tabular}{lll}
\hline Manifestations and treatment & & Classification - initial evaluation \\
\cline { 2 - 3 } & \multicolumn{1}{c}{ Mild } & Moderate \\
\hline Myasthenic facies and blurred vision & Absent or delayed & Discrete or evident \\
Myalgia & Absent or discrete & Discrete \\
Time of coagulation (TC) & Normal or altered & Normal or altered \\
Red or brown urine & Absent & Little evident or absent \\
Oliguria or anuria & Absent & Absent \\
Antivenom (no. vials) ACS/ABCS & 5 & 10 \\
Route of administration & Intravenous & Present \\
\hline
\end{tabular}

ABCS, anti-bothropic-crotalic serum; ACS, anti-crotalic serum. Source: Adapted from the Ministry of Health, 2001.

Table A3 Elapidae accident: classification regarding severity and recommended antivenom

Clinical manifestations

Antivenom (no. vials) AES

Route of administration

Due to the risk of acute respiratory failure, they must be considered severe

10

Intravenous

AES, anti-Elapidae serum. Source: Adapted from PINHO; PEREIRA, 2001. 